EPiC Series in Engineering
Volume 3, 2018, Pages 1513-1522
HIC 2018. 13th International
Conference on Hydroinformatics

\title{
Flow around groynes modelling in different numerical schemes
}

\author{
Quang Binh NGUYEN ${ }^{1}$, Ngoc Duong VO ${ }^{1,2}$, Philippe GOURBESVILLE ${ }^{2}$ \\ ${ }^{1}$ Faculty of Water Resource Engineering, \\ University of Science and Technology, the University of Da Nang, Viet Nam. \\ ${ }^{2}$ Innovative City lab URE 005 \\ Polytech'Nice Sophia, Nice Sophia Antipolis University, France. \\ nqbinh@dut.udn.vn; vo.ngoc.duong@dut.udn.vn; \\ Philippe.GOURBESVILLE@unice.fr
}

\begin{abstract}
There is no need for further augment about the performance of numerical model in representing the hydraulic flow regime. Even if the mathematics and computer science have obtained many considerable progresses, there have not been yet uptil now a numerical solution that is considered comprehensively and perfectly the fluid mechanics due to its complication. Therefore, lot of numerical schemes have been developed relied on different approaches: Advection schemes, diffusion schemes, turbulence models. Model appropriate selection is considered as a key factor to sovle successfully a real problem. With the aims of evaluating the impact of different numerical schemes, this study uses TELEMAC 3D model, a product of EDF, to simulate the hydraulic regime in river. Relying on the advection schemes and turbulence models, five scenarios are organized in TELEMAC 3D for representing the hydraulic flow in a segment of the Waal, Netherlands. The modeling result is compared with the research of Mohamed F.M Yossef and Huid J. de Vriend (2011) in aspect of horizontal velocity distribution, vertical velocity distribution, flow stage. The comparison shows that there is a significant uncertainty in using different numerical schemes for flow stage modeling. The paper is expected to provide an insight view about using the computational model for hydraulic research and to be useful for studying the dynamics of flow stage by hydrodynamics simulation.
\end{abstract}

Keywords: Advection scheme; Turbulence model; Groyne; Waal river; TELEMAC $3 \mathrm{D}$. 


\section{Introduction}

The appearance of unexpected phenomena is inevitable when adding training works to the river. Studying to find out the solution for mitigating the negative impacts of these artificial constructions is necessary in designing process. The training works such as the groyne or spur - dike which are often constructed at an angle to the flow and begin at the riverbank with a root, and end at the desired regulation line with a head. Due to its capacity in maintaining a deep, straight channel for improved navigation, a range of groyne are used to restrict the flow in a narrow channel to keep it away from erodible banks (McCoy, Constantinescu, \& Weber, 2008). Therefore, the adding structures will make a local significant disorder in river flow. Flow around them, in particular flow near groyne, alters complicatedly in three dimensions with different levels. Process consequences are appearance of multiple secondary flows and eddy area which are quite difficult for modeling out of our limited knowledge about the exchange process between groyne fields and main channel (Chrisohoides, Sotiropoulos, \& Sturm, 2003). Even if, these problems have been studied deeply in many aspects from theory, experiment or modeling, the comprehension on them is seemly still not enough to be able to represent accurately the phenomena at groyne area. For example, the famous study of Altunin (1962) supplied an theory about how to determine reasonable design of training work. Recently, due to the development of technology and equipment, many experiments have been realized to find out the effective structure and reasonable placement of groyne. In order to find efficient alternative designs, in the physical, economical, and ecological sense, for the standard groynes for large rivers in Europe, Uijttewaal (2005) released an experiment which concentrated to test the effects of various groyne shapes on the flow in a groyne field. 69 scenarios were run by the equip of Yeo et al. (2005) to get the knowledge for writing down the Korean designed standard of river training works. These experiments concentrated to analyse the arrangements, structure of groyne system in Korean river system. Similarly, Shahrokhi \& Sarveram (2011) also published an experience on 3D simulation for researching the effect of groyne on flow regime.

Although developing on two different methodologies, numerical and experiment, they have given results which are rather similar (Constantinescu, Sukhodolov, \& McCoy, 2009). They have been expected to contribute remarkably for understanding the characteristic of flow, the interaction between the flow and morphology at groyne fields and also in designing the training works. Nevertheless, experiment and modeling methodologies possess particularities which are believed as their advantages and disadvantages. The experiment what is realized via physical modeling is used to apply for designing large constructions (Przedwojski, Błazejewski, \& Pilarczyk, 1995). Because of present technology, this method has been only able to demonstrate its performance in river segments having the simple shape where hydrodynamic regime is not complicated. In the case of complex locations such as junctions, high bathymetry variations or shallow areas, this approach seems inappropriate to simulate flow characteristics. Furthermore, the cost of physical modeling is also a big limitation, especially with medium and small works (Garde, Subramanya, \& Nambudripad, 1961). Inversely, nowadays with the developing of mathematics and computational system, numerical modeling is seen as a convenient, high performance, flexible and low cost tool for analyzing the hydrodynamic characteristics at groyne fields (Ge \& Sotiropoulos, 2005). Lots of models have been developed such as TELEMAC 3D, Delft 3D, FLOW 3D. They have demonstrated their conveniences in comparison with experiment. However, the problem is that the experiment has to be carried out in advance to supply fundamental knowledge for developing the numerical model and also test their capacity.

However, in the context of diversification of numerical schemes to solve hydraulic problem, there is a need to compare their effectiveness towards a real case. In order to make clearer the difference in using different numerical schemes to hydraulic flow regime modelling, especially the flow near groyne, the study is compare five scenarios which are organized from advection schemes and turbulence models to represent the hydraulic flow in a segment of the Waal, Netherlands. The modeling result is compared with the research of Mohamed F.M Yossef and Huid J. de Vriend (2011), aspects - horizontal velocity 
distribution, vertical velocity distribution, turbulence intensity, pressure, flow stage, etc. (Yossef \& de Vriend, 2010). The comparison shows that there is a significant uncertainty using different numerical schemes for flow stage modelling. The paper is expected to provide an insight view about using the computational model for hydraulic research and to be useful for studying the dynamics of flow stage by hydrodynamics simulation.

\section{Methodology}

\subsection{TELEMAC 3D}

The TELEMAC-MASCARET system is a famous product of the National Hydraulic and Environment Laboratory, Electricity of France (EDF). By developing on the finite-element method and using unstructured grid of triangular elements for presenting the space, this systems is expected to be a powerful integrated modeling tool for use in the field of free-surface flows (Hervouet, Razafindrakoto, \& Villaret, 2011). TELEMAC-3D is a three-dimensional computational code describing the 3D velocity field (u, v, w) and the water depth $h$ (and, from the bottom depth, the free surface $S$ ) at each time step. Besides, it solves the transport of several tracers which can be grouped into two categories, namely the socalled "active" tracers (primarily temperature and salinity), which change the water density and act on flow through gravity), and the so-called "passive" tracers which do not affect the flow and are merely transported. (DESOMBRE, 2013). TELEMAC 3D solves problems with two different approaches, the first is based on Navier-Stokes equation with assumption that the equation takes into account the hydatic pressure and the second is with the assumption that the Navier-Stokes equation does not take into account the hydrostatic.

\subsection{Study area}

The Waal is the largest distributary of the Rhine river flowing through Netherlands (Figure 1). This river plays an important role in inland water transport in Europe when is the major waterway connecting the port of Rotterdam to Germany. In order to protect river banks, guarantee a sufficient depth and width for waterway, a major hydraulic engineering work system has been constructs since long time ago. Uptil now, this system reachs to more than 500 groynes with a design quite reasonable (Hoffmans, 2012).

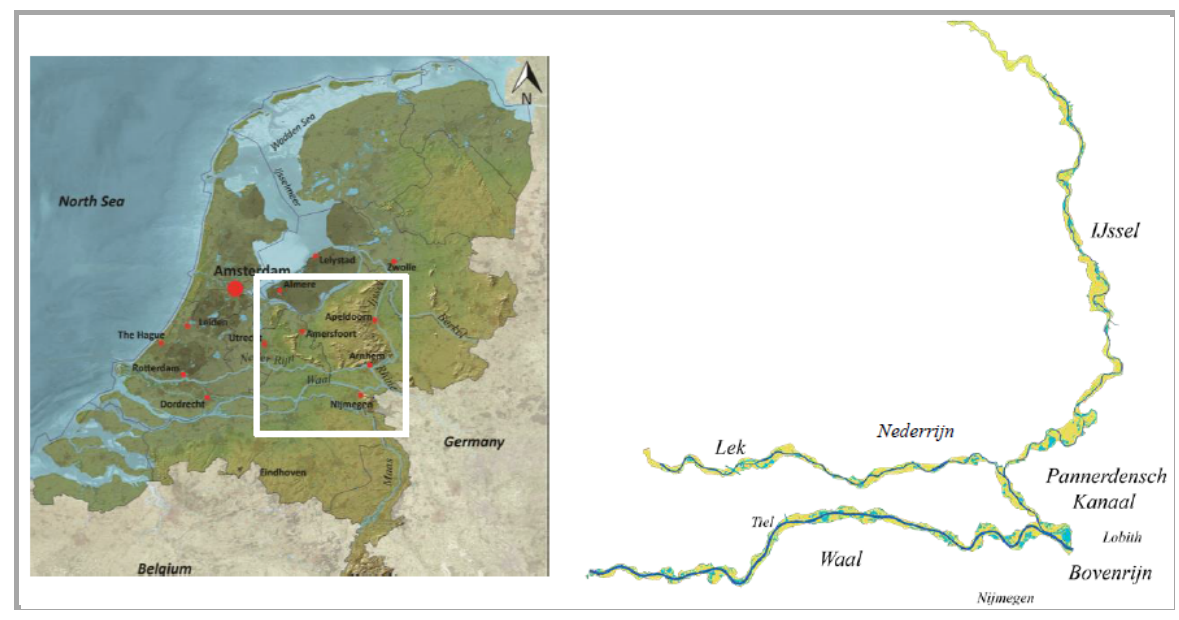

Figure 1: Study area 


\subsection{Model setup}

The model is setup almost similar to the experiment realized in the Laboratory of Fluid Mechanices at Delft University of Technology. All characteristic of experiment flume is represented in TELEMAC $3 \mathrm{D}$ via a mesh with 27200 nodes and 53824 elements. For simulating accurately the flow characteristic, the mesh structure is constructed varying due to bed topography, groyne location and flow regime. Relying on this principle, the mesh in this study is created with three different areas. The first is groyne, around groynes and transition area between groyne field and main channel. The second area is space between groynes. The last is main channel. The mesh density factor is $0.05,0.1$ and 0.15 representatively (Figure 2).

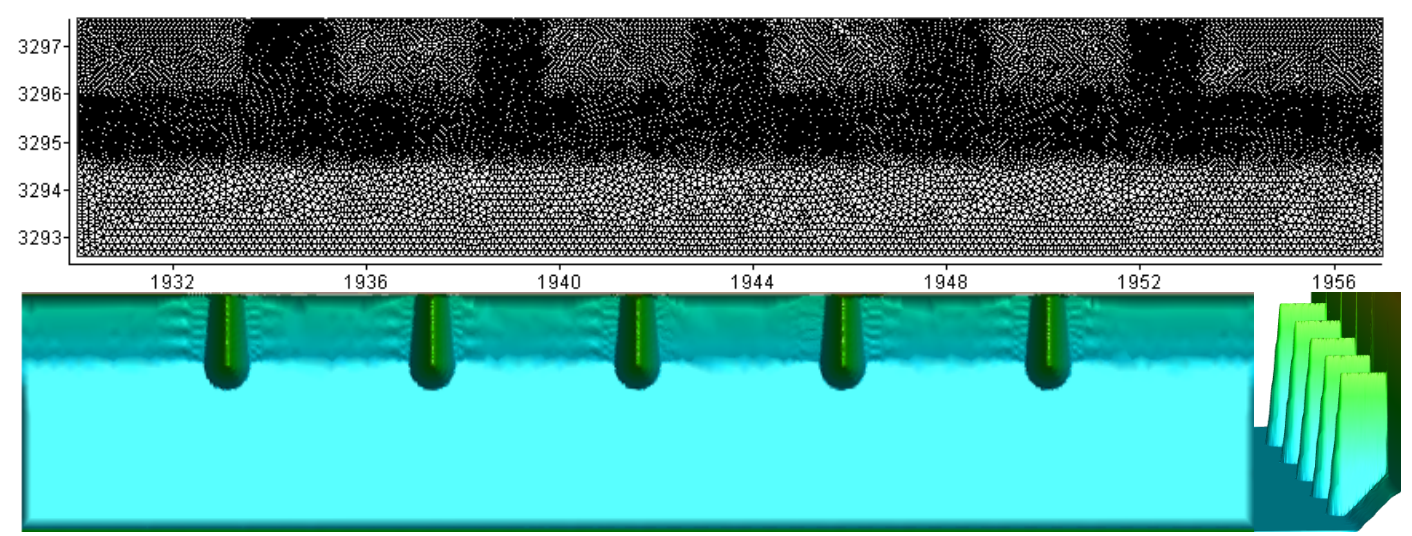

Figure 2: Model setup

Experimental condition, which is key factor decided to the flow stage, is replaced by boundary condition in numerical model. In order to represent the emergent and submerged flow stages like in experiment, the simulation is carried out with two different scenarios, described in boundary condition in table 1 . Following that the mean velocity of main channel is maintained at a constant value about $0.3 \mathrm{~m} / \mathrm{s}$, the flow dynamic variation is depended on water level inputs that are $0.248 \mathrm{~m}, 0.310 \mathrm{~m}$ and $0.357 \mathrm{~m}$ corresponding with three flow stages - Emergence, slightly submergence, fully submergence.

The simulation time is lasted than 1800 s to ensure observing a full coverage of the largest turbulence structure. In comparison with the experiment of Mohamed F.M Yossef and Huid J. de Vriend, the simulation time is longer than three times.

Table 1: Boundary condition

\begin{tabular}{crrr}
\hline No & Stage & Discharge, Q $\left(\mathrm{m}^{3} / \mathrm{s}\right)$ & Water level, $\mathrm{h}(\mathrm{m})$ \\
\hline 1 & Emergence & 0.248 & 0.248 \\
2 & Slightly submergence & 0.305 & 0.310 \\
3 & Fully submergence & 0.381 & 0.357 \\
\hline
\end{tabular}

With the aims of obtaining subcritical flow as observe in prototype, the Froude number (F) in

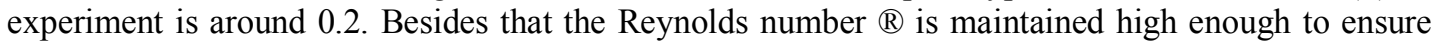
turbulent flow in both channel region $(\mathrm{R} \cong 6.106)$ and groyne fields region $(\mathrm{R} \cong 6.104)$. In the TELEMAC 3D model, the Manning Coefficient is setup variously to agree with above conditions. Depending on flume material, after model calibration, the manning number is defined for two regions as the table 2 .

Table 2: Manning Coefficient

\begin{tabular}{rr}
\hline Polygons & Manning, $\mathrm{n}$ \\
\hline Groyne and groyne field & 0.015 \\
Main channel & 0.025 \\
\hline
\end{tabular}


As presented above, in this study the model is set up with five different scenarios as Table 3 in order to estimate the effect of the Advection scheme and the Turbulence model.

Table 3: Case setup

\begin{tabular}{rrr}
\hline Case & Advection scheme & Turbulence model \\
\hline Case & Characteristices & Prandtl Mixing Length (PML) \\
Case & Streamline Upwind Petrov Galerkin (SUPG) & Prandtl Mixing Length (PML) \\
Case & Leo Postma & $\mathrm{k}-\varepsilon$ \\
Case & Multidimensional Upwind Residual Distribution & $\mathrm{k}-\varepsilon$ \\
Case & Positive Steamwise Invariant (MURD PSI) & $\mathrm{k}-\varepsilon$ \\
\hline
\end{tabular}

\section{Results and Discussion}

In order to make clear the uncertainties in using different Advection scheme and Turbulence model, the result will be analyzed in three aspects: velocity distribution, presseure which characterized for turbulent flow, and computational time.

\subsection{Velociy distribution}

The study of horizontal velocity in the case of emergence is presented the figure 3 . Follow that, the horizontal velocity distribution in scenario $3,4,5$ is similar. This value is smaller than the velocity of scenario 1 , and 2 . These differences are demonstrated more detailed in figure 4 .

The Figure 4 also shows that the case 3, 4, 5 using combinedly between the Advection scheme: Leo Postma, MURD, MURD PSI and Turbulence model $\mathrm{k}-\varepsilon$ give the result mostly similar to the experiment of Mohamed F.M Yossef and Huid J. de Vriend. The main eddy distributes almost 2/3 area between groynes. The velocity between groynes is smaller than main channel one arround $60 \%-70 \%$. Furthermore, it appears the second eddies and roving eddies around groyne 3. In remaining cases, the flow state is a little different in comparison with experiment. The main eddy at case 1 appears closer to groyne 4 and distributes near to main stream. The velocity in this case is only $10 \%$ to $20 \%$ of the one in main stream. Contrariwise, the flow state of case 2 is quite different with above cases and different with the experiment. The main eddy in this case is smaller than second eddies.

Table 4: Error analysis of velocity

\begin{tabular}{|c|c|c|c|c|c|c|c|c|c|c|}
\hline \multirow[t]{3}{*}{ State } & \multicolumn{10}{|c|}{ Error } \\
\hline & \multicolumn{2}{|c|}{ Case 1} & \multicolumn{2}{|r|}{ Case 2} & \multicolumn{2}{|c|}{ Case 3} & \multicolumn{2}{|c|}{ Case 4} & \multicolumn{2}{|c|}{ Case 5} \\
\hline & $\operatorname{RMSE}(\mathrm{m} / \mathrm{s})$ & $\mathrm{R}^{2}$ & $\begin{array}{r}\text { RMSE } \\
(\mathrm{m} / \mathrm{s})\end{array}$ & $\mathrm{R}^{2}$ & $\begin{array}{r}\text { RMSE } \\
(\mathrm{m} / \mathrm{s})\end{array}$ & $\mathrm{R}^{2}$ & $\begin{array}{r}\text { RMSE } \\
(\mathrm{m} / \mathrm{s})\end{array}$ & $\mathrm{R}^{2}$ & $\begin{array}{r}\text { RMSE } \\
(\mathrm{m} / \mathrm{s})\end{array}$ & $\mathrm{R}^{2}$ \\
\hline Emergence & 0.0478 & $\begin{array}{r}0.8 \\
9\end{array}$ & 0.1727 & $\begin{array}{r}0.8 \\
9\end{array}$ & 0.0582 & $\begin{array}{r}0.9 \\
0\end{array}$ & 0.0591 & $\begin{array}{r}0.9 \\
1\end{array}$ & 0.0582 & $\begin{array}{r}0.9 \\
0\end{array}$ \\
\hline Slightly submergence & 0.0792 & $\begin{array}{r}0.7 \\
6\end{array}$ & 0.0973 & $\begin{array}{r}0.8 \\
5\end{array}$ & 0.1097 & $\begin{array}{r}0.6 \\
8\end{array}$ & 0.0990 & $\begin{array}{r}0.8 \\
6\end{array}$ & 0.0872 & $\begin{array}{r}0.8 \\
3\end{array}$ \\
\hline Fully submergence & 0.0834 & $\begin{array}{r}0.7 \\
4\end{array}$ & 0.1676 & $\begin{array}{r}0.9 \\
0\end{array}$ & 0.1278 & $\begin{array}{r}0.8 \\
5\end{array}$ & 0.0470 & $\begin{array}{r}0.8 \\
9\end{array}$ & 0.0870 & $\begin{array}{r}0.9 \\
2\end{array}$ \\
\hline
\end{tabular}



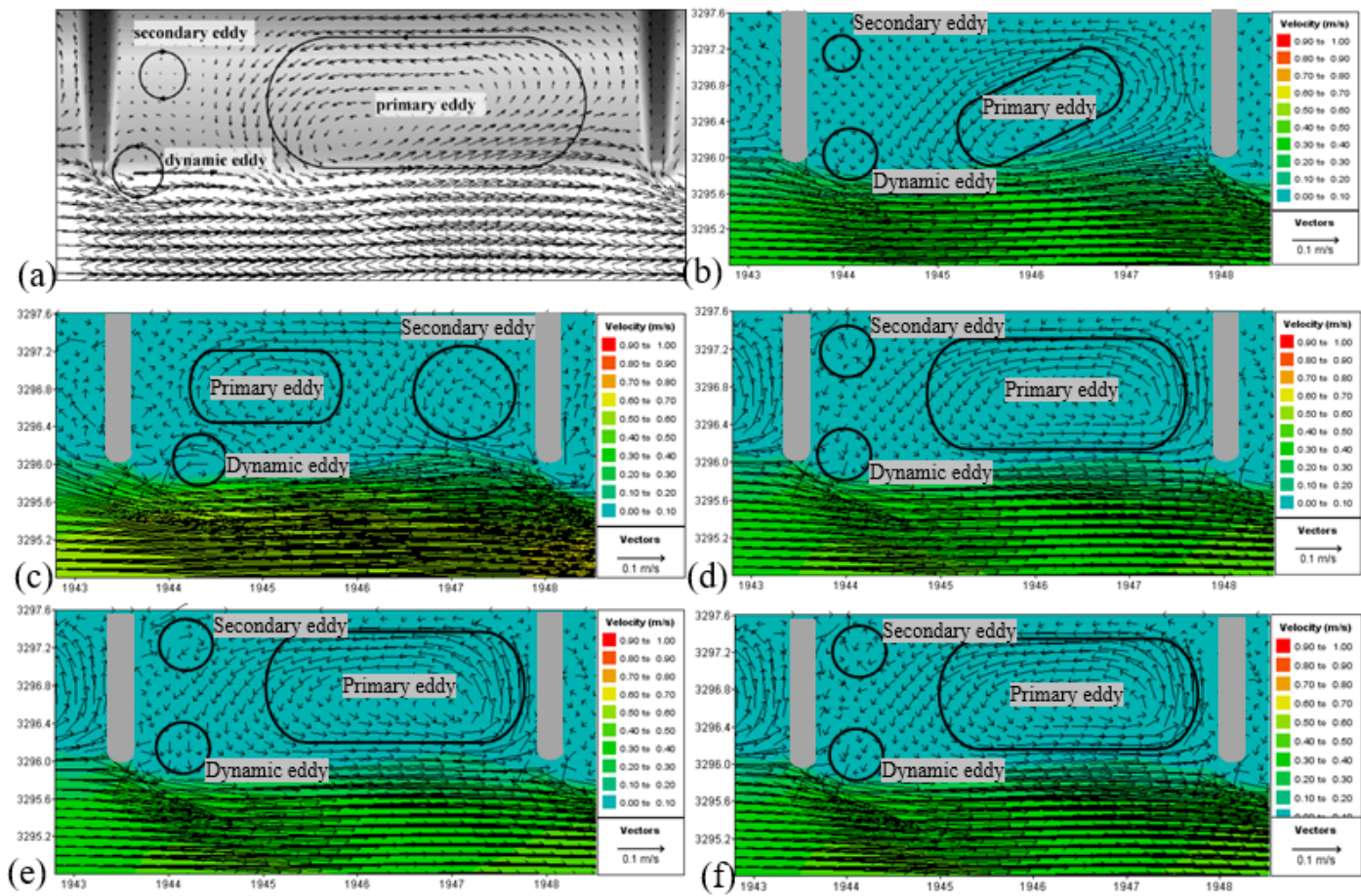

Figure 4: The flow velocity distribution at groyne 4 in emergent case

(a) Experiment; (b) Characteristices và PML; (c) SUPG và PML; (d) Leo Postma và $\mathrm{k}-\varepsilon$; (e) MURD và $\mathrm{k}-\varepsilon$; (f) MURD PSI và $\mathrm{k}-\varepsilon$.
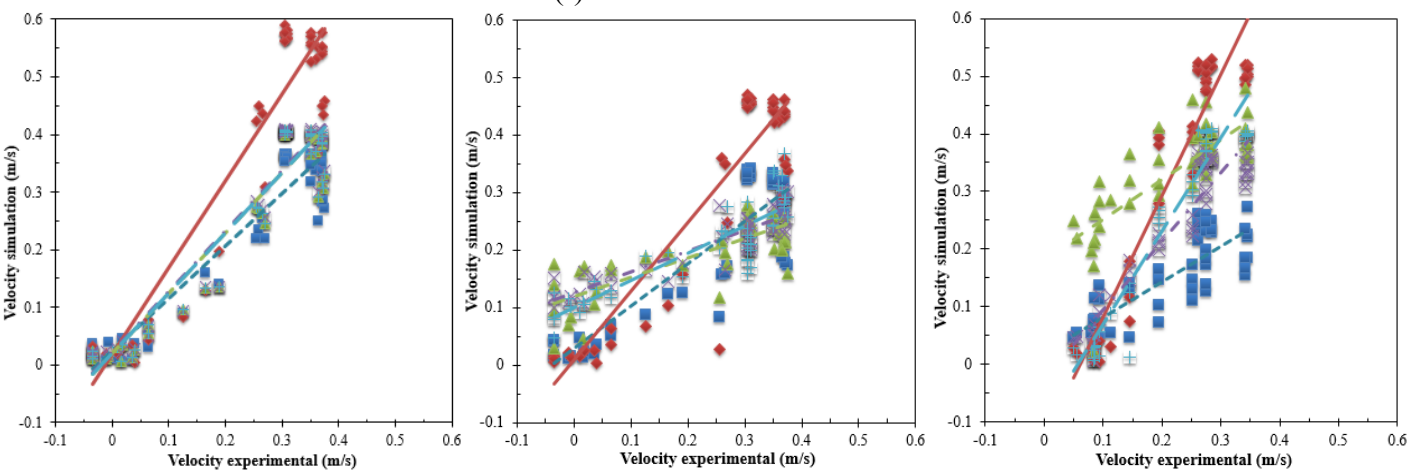

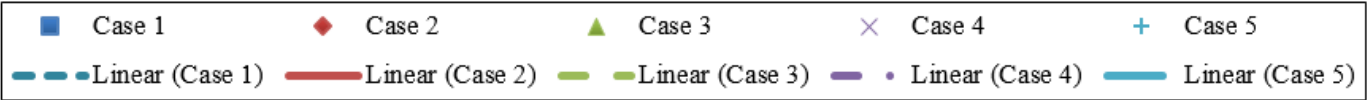

(a)

(b)

(c)

Figure 5: Correlation chart of velocity. (a) Emergence, (b) Slightly submergence, (c) Fully submergence

The result shows that the in most case, the biggest difference between simulation and experiment appears at bank and intersection part of main channel and groynes. The Figure 4, Figure 5 and Table 4 demonstrate that the simulations in emergence flow state give the result more reasonable in comparison with remaining simulation and the most appropriate with the experiment. The velocity error of emergence cases is almost smaller than $0.06 \mathrm{~m} / \mathrm{s}$ and the $\mathrm{R} 2$ index is quite high, reach to 0.89 . The modelling also express that in the case of slightly submergence, the result is dissimilar to emergence and fully submergence. 


\subsection{Pressure}

The chaotic change in pressure and velocity are considered as key factors decided the turbulent flow regime. Therefore, different numerical scheme application is expected to cause a big variaton towards pressure factors. In the case of turbulent state, shear stress is the pressure component which express essentilly the interaction of fluid element. Thus, this part will only concentrate to analyze the flunctuation of tangential stress. The change is expressed via Figure 6 to 8 . These are the shear stress at four cross sections A, B, C, D in groyne 4.
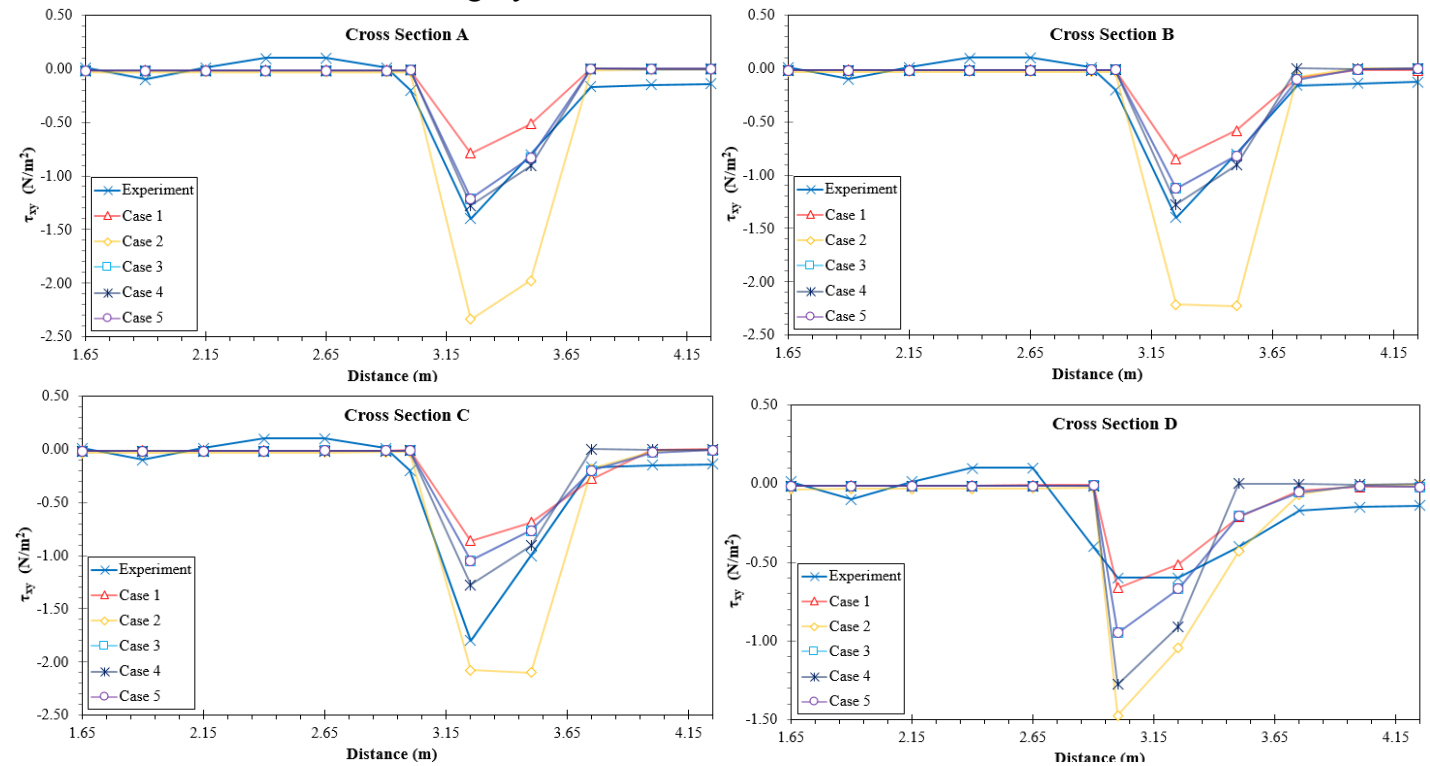

Figure 6: Shear stress in case of emergent flow
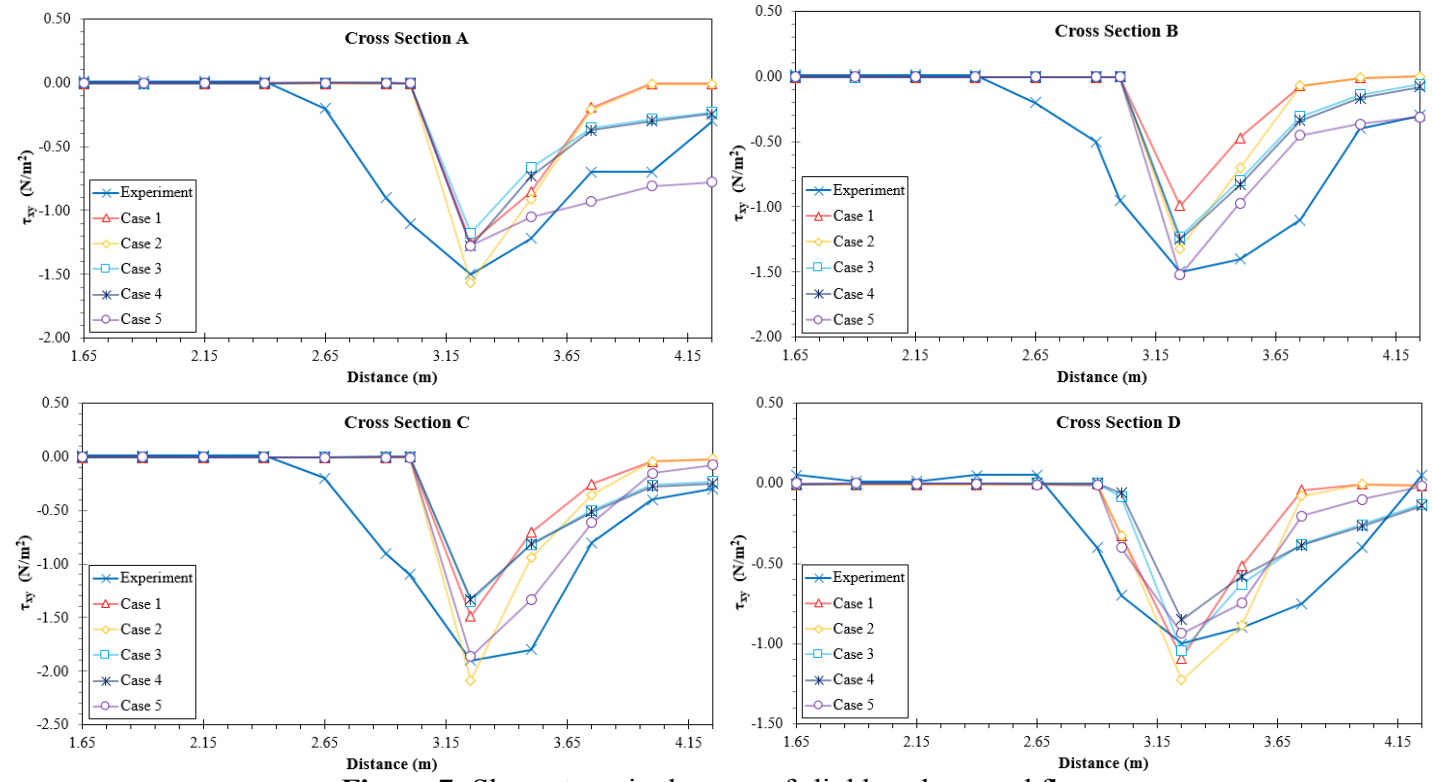

Figure 7: Shear stress in the case of slighly submerged flow 

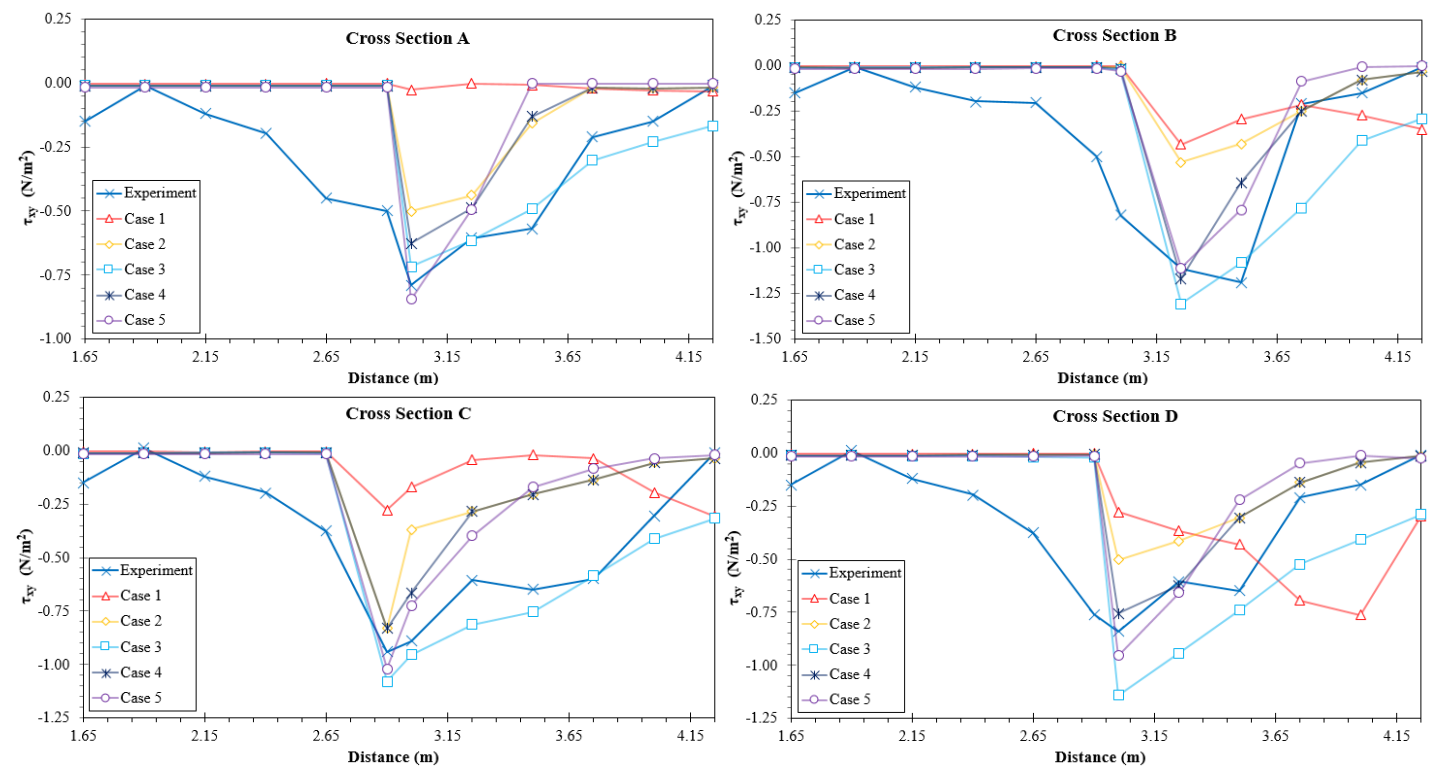

Figure 8: Shear stress in the case of fullysubmerged flow

As shown in the section 3.1, the velocity in case 2 is bigger than remaining cases and experiment of Mohamed F.M Yossef and Huid J. de Vriend, it is not so supprised when shear stress of case 4 is bigger than others, especially in the case of emergence (Figure 6). This value is multiple 2 time in comparison with the experioment. On the contrary, the result is smaller than the experiment at all three flow states. Futhermore, the change tendency along to four cross sections of fully submeged stat of case 1 is abnomal to others. With the case $3,4,5$ the result are mostlt similar and apropriate to experiment.

\subsection{Computation time}

Computation time is thought to be one of decisive factors in numerical modelling. The faster speed will be useful for solving big problem as well as giving more results in short time. In this study, the time is also considered. Comparing in $0.1 \mathrm{~s}$ time step and 1800s simulated time, the case 1 and case 2 which applied the SUPG Advection scheme (combined with the PML Turbulence model give the shortest time. Conversely, the time in remaining cases is longer two times in comparison with case 1 and case 2 (Figure 9).

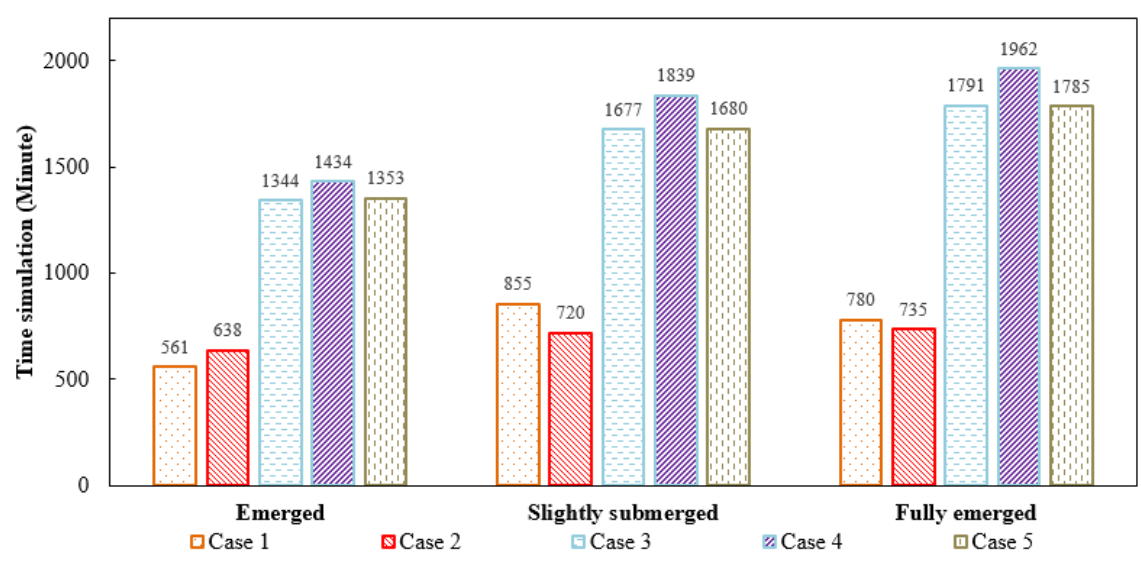

Figure 9: Time simulation 


\section{Conclusions}

The result demonstrates that there is a big uncertainty when using different numerical schemes. This is presented in both sides, the distribution of Horizontal velocity and flow state at the cross sections. The scenario which combine between Advection schemes: Leo Postma, MURD, MURD PSI and Turbulence model $\mathrm{k}-\varepsilon$ give the result mostly similar to the experiment of Mohamed F.M Yossef and Huid J. de Vriend. Meanwhile, the test with emergence flow state give the result more reasonable in comparison with remaining simulation and the most appropriate with the experiment. Moreover, the chaotic change in pressure is also considerd. The fluctuation of shear stress contributes a strong proof for the affect of different numerical schemes on simulated flow state. The proof might provide basic point of view for choosing the numerical schemes.

The performance of the simulation demonstrates the strong capacity of computational modeling systems like TELEMAC-3D in representing the flow stage in different cases. The result also confirms preeminence of computational program about flexibility, simulated time and result expression in comparison with experiment.

The result demonstrates that there is a big uncertainty when using different numerical schemes. This is presented in both sides, the distribution of Horizontal velocity and flow state at the cross sections. The scenario which combine between Advection schemes: Leo Postma, MURD, MURD PSI and Turbulence model $\mathrm{k}-\varepsilon$ give the result mostly similar to the experiment of Mohamed F.M Yossef and Huid J. de Vriend. Meanwhile, the test with emergence flow state give the result more reasonable in comparison with remaining simulation and the most appropriate with the experiment. Moreover, the chaotic change in pressure is also considerd. The fluctuation of shear stress contributes a strong proof for the affect of different numerical schemes on simulated flow state. The proof might provide basic point of view for choosing the numerical schemes.

The performance of the simulation demonstrates the strong capacity of computational modeling systems like TELEMAC-3D in representing the flow stage in different cases. The result also confirms preeminence of computational program about flexibility, simulated time and result expression in comparison with experiment.

\section{References}

Altunin, S. T. (1962). Channel Regulation. Sel'khozizdat, Moscow.

Chrisohoides, A., Sotiropoulos, F., \& Sturm, T. W. (2003). Coherent structures in flat-bed abutment flow: Computational fluid dynamics simulations and experiments. Journal of Hydraulic Engineering, 129(3), 177-186.

Constantinescu, G., Sukhodolov, A., \& McCoy, A. (2009). Mass exchange in a shallow channel flow with a series of groynes: LES study and comparison with laboratory and field experiments. Environmental Fluid Mechanics, 9(6), 587-615.

DESOMBRE, J. (2013). TELEMAC MODELLING SYSTEM - TELEMAC-3D Software, Operating manual.

Garde, Rj., Subramanya, K., \& Nambudripad, K. D. (1961). Study of scour around spur-dikes. Journal of the Hydraulics Division, 86, 23-37. JOUR.

Ge, L., \& Sotiropoulos, F. (2005). 3D unsteady RANS modeling of complex hydraulic engineering flows. I: Numerical model. Journal of Hydraulic Engineering, 131(9), 800-808.

Hervouet, J. M., Razafindrakoto, E., \& Villaret, C. (2011). Dealing with dry zones in free surface flows: a new class of advection schemes. In Proceedings of the 34th World Congress of the International Association for Hydro-Environment Research and Engineering: 33rd Hydrology and Water Resources Symposium and 10th Conference on Hydraulics in Water Engineering (p. 4103). 
Engineers Australia.

Hoffmans, G. J. C. M. (2012). The influence of turbulence on soil erosion (Vol. 10). Eburon Uitgeverij BV.

McCoy, A., Constantinescu, G., \& Weber, L. J. (2008). Numerical investigation of flow hydrodynamics in a channel with a series of groynes. Journal of Hydraulic Engineering, 134(2), 157172.

Przedwojski, B., Błazejewski, R., \& Pilarczyk, K. W. (1995). River training techniques: fundamentals, design and applications. AA Balkema.

Shahrokhi, M., \& Sarveram, H. (2011). Three-dimensional simulation of flow around a groyne with large-eddy turbulence model. Journal of Food, Agriculture \& Environment, 9(3\&4), 677-681.

Uijttewaal, W. S. (2005). Effects of groyne layout on the flow in groyne fields: Laboratory experiments. Journal of Hydraulic Engineering, 131(9), 782-791.

Yeo, H. K., Kang, J. G., \& Kim, S. J. (2005). An experimental study on tip velocity and downstream recirculation zone of single groynes of permeability change. KSCE Journal of Civil Engineering, 9(1), 29-38.

Yossef, M. F. M., \& de Vriend, H. J. (2010). Flow details near river groynes: experimental investigation. Journal of Hydraulic Engineering, 137(5), 504-516. 